\title{
Changes in Growth and Photosynthetic Capacity of Cucumber Seedlings in Response to Nitrate Stress
}

\author{
Xiaoyu Yang ${ }^{1,3}$, Xiufeng Wang ${ }^{1,2 *}$, Min Wei ${ }^{1,2}$, Shoko Hikosaka ${ }^{3}$, Eiji Goto ${ }^{3}$ \\ ${ }^{1}$ College of Horticulture Science and Engineering, Shandong Agricultural University, Tai'an, Shandong, 271018, PR \\ China; \\ ${ }^{2}$ State Key Laboratory of Crop Biology, Tai'an, Shandong, 271018, PR China; \\ ${ }^{3}$ Graduate School of Horticulture, Chiba University, Matsudo, Chiba, 271-8510, Japan
}

*Corresponding author, Tel: +86-538-8242456 Fax: +86-538-8246017 E-mail: xfwang@sdau.edu.cn Received: 28 November 2009; Accepted: 01 March 2010.

\begin{abstract}
The effects of three nitrate levels - 14(CK), 56(T-1), and $140 \mathrm{mmol}^{-1}$ (T-2) - on growth and photosynthetic capacity of cucumber (Cucumis sativus L. cv. Xintaimici) seedlings grown in hydroponic culture were investigated. The results showed that at $12 \mathrm{~d}$ after treatment plant height, stem diameter, leaf area, and leaf number of cucumber seedlings were stimulated by $56 \mathrm{mmol} \mathrm{L}^{-1}$ nitrate, whereas were inhibited significantly by $140 \mathrm{mmol}^{\mathrm{L}^{-1}}$ nitrate compared with CK. Short-term stimulation in photosynthetic rate occurred under T-1 treatment, and then recovered to the level of CK. Photosynthetic rate of T-2 seedlings significantly decreased over treatment course with respect to CK. Photosynthetic pigment content of T-1 and T-2 increased during the first $2 \mathrm{~d}$, and gradually recovered to the level of CK thereafter. Chlorophyll $\mathrm{a} / \mathrm{b}$ and carotenoids/chlorophyll of $\mathrm{T}-1$ had no significant difference from $\mathrm{CK}$ during treatment period. During the first $4 \mathrm{~d}$, there was no significant difference in chlorophyll $\mathrm{a} / \mathrm{b}$ and carotenoids/chlorophyll between T-2 and CK. After $4 \mathrm{~d}$, chlorophyll $\mathrm{a} / \mathrm{b}$ of T-2 increased gradually, whereas carotenoids/chlorophyll decreased. Actual PSIl efficiency ( $\left.\Phi_{\mathrm{PSII}}\right)$ and photochemical quenching (qP) of T-1 had no significant difference from CK, and non-photochemical quenching $(q N)$ was a little higher than CK after $2 \mathrm{~d}$. During the first $2 \mathrm{~d}$, there was little difference in $\Phi_{\mathrm{PS} \|}$ and $\mathrm{qP}$ between T-2 and CK. After $2 \mathrm{~d}$, both $\Phi_{\mathrm{PS} \|}$ and $\mathrm{qP}$ of T-2 decreased to a great extend. A significant increase in qN of T-2 occurred over treatment course. With respect to CK, Hill reaction activity of T-1 slightly decreased, and $\mathrm{T}-2$ treatment resulted in a significant decrease of Hill reaction activity. This evidence indicates that high-level nitrate stress may reduce photosynthesis through its effects not only on stomatal conductance but on the photosynthetic apparatus.
\end{abstract}

Key words: chlorophyll a fluorescence; Hill reaction; photosynthetic pigment content; photosynthetic rate

\section{INTRODUCTION}

Nitrogen, often a limiting resource for plant growth, is required by plants in great quantities than any other mineral element. Thus the availability of nitrogen is a significant determinant of crop yield (Foyer and Noctor, 2002). Complicating this for agriculture is the fact that often less than $50 \%$ of nitrogen fertilizer applied ultimately may be utilized by crops because nitrate ion is highly mobile and not absorbed by soil colloid (Allison, 1966). To satisfy the nitrogen demand, farmers often add nitrogen in large quantities to maintain adequate level in the rhizosphere (Zhu et al., 2005). This excessive use of nitrogen fertilizer has resulted in undesirable conditions such as the accumulation of nitrate in plant and soil. The large accumulation of nitrogen in the soil, on one hand, has contaminated the ground water (Barker and Mills, 1980), 
on the other hand resulted in soil secondary salinization in protected farmland because of a lack of leaching by rainfall and strong evaporation of soil water (Kitamura et al., 2006).

China has the largest area of protected crops and is now the leading country in the world for protected agriculture, including multi-span greenhouse, solar lean-to greenhouse and plastic tunnels (Jiang and Du, 2000). However, soil secondary salinization has seriously limited sustainable development of agricultural production in protected farmland of China (Yu et al., 2005). According to the previous studies (Ju et al., 2007; Yu et al., 2005), accumulation of ions in protected farmland is greatly different from ordinary soil salinization. In protected farmland, the main cation and anion are $\mathrm{Ca}^{2+}, \mathrm{K}^{+}$and $\mathrm{NO}_{3}{ }^{-}$, respectively, while $\mathrm{Na}^{+}$and $\mathrm{Cl}^{-}$are the main forms of ions in ordinary soil salinization.

In the past several years, most of studies about salt stress to plant have been focused on $\mathrm{NaCl}$ (Debouba et al., 2007; Liu and Zhu, 1998; Stepien and Johnson, 2009; Zhu, 2002), however, there have been few investigations about nitrate stress in horticultural crops. Cucumber is one of the most important horticultural crops, and it has been reported that excessive accumulation of nitrate widely inhibits the growth and development of cucumber in protected farmland of China (Gao et al., 2008; Lü et al., 2007), while the underlying mechanisms are still not well understood. Photosynthesis is the fundamental metabolic process and plays a critical role in plant growth and development. This process is very sensitive to environmental stress. Drought (Lauteri et al., 1997), salt stress (Bongi and Loreto, 1989), and leaf aging (Loreto et al., 1994) all result in inhibition of photosynthesis because of the reduction of conductance to $\mathrm{CO}_{2}$ diffusion in the leaf mesophyll (Delfine et al., 1999). But little information about changes of photosynthesis under nitrate stress exists. Therefore, we studied how excessive nitrate influenced the growth and photosynthetic capacity of cucumber seedlings. Plant growth, photosynthetic rate, photosynthetic pigment content, chlorophyll a fluorescence and Hill reaction activity were measured in nitrate-stressed cucumber seedlings under greenhouse conditions.

\section{MATERIALS AND METHODS}

Plants, growth conditions, and experimental design: Cucumber (Cucumis sativus L. cv. Xintaimici, mid-tolerant to salinity stress), was used in all experiments. The seeds were sterilized with a sodium hypochlorite solution (5\% active $\mathrm{Cl}$ ) for $5 \mathrm{~min}$, washed five times, and soaked in deionized water for $12 \mathrm{~h}$. The soaked seeds were raised in well-washed quartz sand and irrigated with tap water. The experiments were carried out in the greenhouse of Shandong Agricultural University from September to November in 2006. When plants had one fully expanded leaf, they were removed from the trays and their roots were washed with tap water to remove the substrate from the roots, and then transplanted to hydroponic boxes $(40 \mathrm{~cm} \times 30 \mathrm{~cm} \times 12 \mathrm{~cm}$, 8 plants per box) containing a complete cucumber nutrient solution (Table 1). The solution was continually aerated with an electric pump. The $\mathrm{pH}$ of nutrient solution was adjusted to $6.0 \pm 0.5$ by addition of $98 \%$ (W/W) $\mathrm{H}_{2} \mathrm{SO}_{4}$. The nutrient solutions in all the hydroponic boxes were completely renewed every four days. When the seedlings had developed three fully expanded leaves, nitrate was dissolved in nutrient solution directly. The excess nitrate test was carried out in a completely randomized design with a split plot arrangement of three replications, providing 8 plants per replication. Three treatments were applied (Table 2):

(CK) complete nutrient solution (control);

(T-1) complete nutrient solution $+\mathrm{Ca}\left(\mathrm{NO}_{3}\right)_{2} 10.5 \mathrm{mmol} \cdot \mathrm{L}^{-1}+$ $\mathrm{KNO}_{3} 21 \mathrm{mmol} \cdot \mathrm{L}^{-1}$;

(T-2) complete nutrient solution $+\mathrm{Ca}\left(\mathrm{NO}_{3}\right)_{2} 31.5 \mathrm{mmol} \cdot \mathrm{L}^{-1}+$ $\mathrm{KNO}_{3} 63 \mathrm{mmol} \cdot \mathrm{L}^{-1}$.

At $0,1,2,4,6,8$, and $12 \mathrm{~d}$ of exposure to treatment, the second fully expanded leaves, counted from the top of seedlings, weresampled forthemeasurement of photosynthetic rate, chlorophyll content, chlorophyll a fluorescence and Hill reaction activity. At $12 \mathrm{~d}$ of exposure to treatment, 6 plants per treatment were collected for the determination of plant growth. 
Table 1. Components of the complete cucumber nutrient solution (Guo, 2004)

\begin{tabular}{cc}
\hline Nutrient Chemicals & Concentration $\left(\mathrm{mmol} \mathrm{L}^{-1}\right)$ \\
\hline $\mathrm{Ca}\left(\mathrm{NO}_{3}\right)_{2}$ & 3.5 \\
$\mathrm{KNO}_{3}$ & 7 \\
$\mathrm{KH}_{2} \mathrm{PO}_{4}$ & 1 \\
$\mathrm{MgSO}_{4}$ & 2 \\
$\mathrm{H}_{3} \mathrm{BO}_{3}$ & 0.05 \\
$\mathrm{Na}_{2} \mathrm{FeEDTA}$ & 0.05 \\
$\mathrm{MnSO}_{4}$ & 0.01 \\
$\mathrm{ZnSO}_{4}$ & 0.0008 \\
$\mathrm{CuSO}_{4}$ & 0.0003 \\
$\left(\mathrm{NH}_{4}\right)_{\mathrm{MO}_{7} \mathrm{O}_{24}}$ & 0.02 \\
\hline
\end{tabular}

Table 2. Nitrate concentration and osmotic potential of nutrient solution

\begin{tabular}{cccccc}
\hline Treatment & $\begin{array}{c}\mathrm{Ca}\left(\mathrm{NO}_{3}\right)_{2} \\
\left(\mathrm{mmol} \mathrm{L}^{-1}\right)\end{array}$ & $\begin{array}{c}\mathrm{KNO}_{3} \\
\left(\mathrm{mmol} \mathrm{L}^{-1}\right)\end{array}$ & $\begin{array}{c}\mathrm{NO}_{3}^{-} \\
\left(\mathrm{mmol} \mathrm{L}^{-1}\right)\end{array}$ & $\begin{array}{c}\text { Osmotic } \\
\text { potential } \\
\text { before } \\
\text { treatment } \\
(\mathrm{MPa})\end{array}$ & $\begin{array}{c}\text { Osmotic } \\
\text { potential } \\
\text { after } \\
\text { treatment } \\
\text { for 3 d } \\
(\mathrm{MPa})\end{array}$ \\
\hline $\mathrm{CK}$ & 3.5 & 7 & 14 & -0.256 & -0.218 \\
$\mathrm{~T}-1$ & 14 & 28 & 56 & -0.341 & -0.315 \\
$\mathrm{~T}-2$ & 35 & 70 & 140 & -0.57 & -0.567 \\
\hline
\end{tabular}

Determination of plant growth: Plant height was measured from the border of the container to the top of the main plant stem with stainless steel ruler $(500 \mathrm{~mm}$, Kenta, Singapore). Stem diameter was measured at the border of the container with vernier caliper (530-101, Mitutoyo, Japan). Leaf area was calculated from leaf length and breadth according to the method of Robbins and Pharr (1987). The number of completely expended leaves was counted and recorded on each plant.

Determination of photosynthetic rate: Photosynthetic rate of individual leaf was measured with an open photosynthesis system (Ciras-II, PPsystems, UK) at 10:00 $\mathrm{HR}$ in the morning. The photosynthetic chamber provides leaf area of $2.5 \mathrm{~cm}^{2}$, leaf temperature of $25^{\circ} \mathrm{C}$, relative humidity of $90 \%$, leaf to air vapor pressure of $200 \mathrm{mbar}$, light intensity of $800 \mu \mathrm{mol} \mathrm{m}^{-2} \mathrm{~s}^{-1}$, and $\mathrm{CO}_{2}$ concentration of 380 $\mu \mathrm{mol} \mathrm{mol}^{-1}$.
Determination of photosynthetic pigment content: Chlorophyll and carotenoids were measured by extracting fresh leaf tissue in $80 \%$ acetone. The absorbance of the centrifuged extract was determined at 663,645 , and 440 $\mathrm{nm}$. Chlorophyll and carotenoids content were calculated by the methods described before (Ikan, 1969; Strain and Svec, 1966).

Determination of chlorophyllafluorescence:Chlorophyll a fluorescence was measured at room temperature with a portable fluorometer (FMS-2, Hansatech, UK). The experiment protocol described before (Genty et al., 1989) was basically followed. Fluorescence nomenclature was according to van Kooten and Snel (1990). All samples were dark-adapted for 30 min prior to fluorescence measurement.

Dark-adapted minimal fluorescence (Fo) with all PSII reaction centers open was measured by the measuring modulated light $\left(<0.1 \mu \mathrm{mol} \mathrm{m} \mathrm{m}^{-2} \mathrm{~s}^{-1}\right)$, which was sufficiently low not to induce any significant variable fluorescence. Darkadapted maximal fluorescence (Fm) with all PSII reaction centers closed was determined by $0.8 \mathrm{~s}$ saturating pulse at $8000 \mu \mathrm{mol} \mathrm{m} \mathrm{m}^{-2} \mathrm{~s}^{-1}$. The leaves were then continuously illuminated with white actinic at an intensity of $300 \mu \mathrm{mol} \mathrm{m}{ }^{-2}$ $\mathrm{s}^{-1}$. Fluorescence in steady state (Fs) was thereafter recorded and a second saturating pulse at $8000 \mu \mathrm{mol} \mathrm{m} \mathrm{m}^{-2} \mathrm{~s}^{-1}$ was imposed to determine light-adapted maximal fluorescence $\left(\mathrm{Fm}^{\prime}\right)$. The actinic light was removed and minimal light-adapted fluorescence level ( Fo') was determined by illuminating the leaf with $3 \mathrm{~s}$ far-red light. All measurements of $\mathrm{Fo}_{0}$ and $\mathrm{Fo}^{\prime}$ were performed with the measuring beam set to a frequency of $600 \mathrm{~Hz}$, whereas all measurements of $\mathrm{Fm}$ and $\mathrm{Fm}^{\prime}$ were performed with the measuring beam automatically switching to $20 \mathrm{kHz}$ during the saturating flash.

By using fluorescence parameters determined in both lightand dark-adapted leaves, calculations of actual PSII efficiency $\left(\Phi_{\text {PSII }}\right)$, photochemical quenching (qP), and non- photochemical quenching (qN) were made of: (1) $\Phi_{\mathrm{PSI}}=\left(\mathrm{Fm}^{\prime}-\mathrm{Fs}\right) / \mathrm{Fm}^{\prime}$, (2) $\mathrm{qP}=\left(\mathrm{Fm}^{\prime}-\mathrm{Fs}\right) /\left(\mathrm{Fm}^{\prime}-\mathrm{Fo}^{\prime}\right),(3) \mathrm{qN}=1-\left(\mathrm{Fm}^{\prime}-\mathrm{Fo}^{\prime}\right) /(\mathrm{Fm}-\mathrm{Fo})$.

Isolation of chloroplasts and determination of Hill reaction activity: Chloroplasts were isolated from the leaves of cucumber seedlings in $0.05 \mathrm{~mol} \mathrm{~L}^{-1}$ Tris- $\mathrm{HCl}$ buffer, $\mathrm{pH} 7.6$, 
containing $0.4 \mathrm{~mol}$ sucrose and $0.01 \mathrm{~mol} \mathrm{NaCl}$ as described by Gorham (1955) with some modifications. The chloroplasts were washed twice in the extraction buffer and finally suspended in the extraction buffer. The Hill reaction activity of the isolated chloroplasts was measured by the rate of photoreduction of $\mathrm{K}_{3} \mathrm{Fe}(\mathrm{SCN})_{6}$ as described by Vishniac (1957) with some modifications. The reaction mixture (final volume 3 $\mathrm{ml}$ ) contained in mmol: Tris-HCl buffer, pH 7.6, 50; $\mathrm{MgCl}_{2}, 5$; $\mathrm{K}_{3} \mathrm{Fe}(\mathrm{SCN})_{6}$, 2; chloroplast preparation containing about $20 \mu \mathrm{g}$ of chlorophyll. The tubes were illuminated at $300 \mu \mathrm{mol} \mathrm{m}^{-2} \mathrm{~s}^{-1}$ of light intensity in the $4{ }^{\circ} \mathrm{C}$ water bath. The decrease in $\mathrm{OD}_{420}$ after 1 min was immediately measured with spectrometer (160 A, Shimadzu, Japan). Tube kept in complete darkness served as reagent blank. The Hill activity was calculated as $\mu \mathrm{mol}$ of reduced $\mathrm{K}_{3} \mathrm{Fe}(\mathrm{SCN})_{6} \mathrm{~h}^{-1} \mathrm{mg}^{-1}$ chlorophyll. Chlorophyll content of the preparation was determined with the method above.
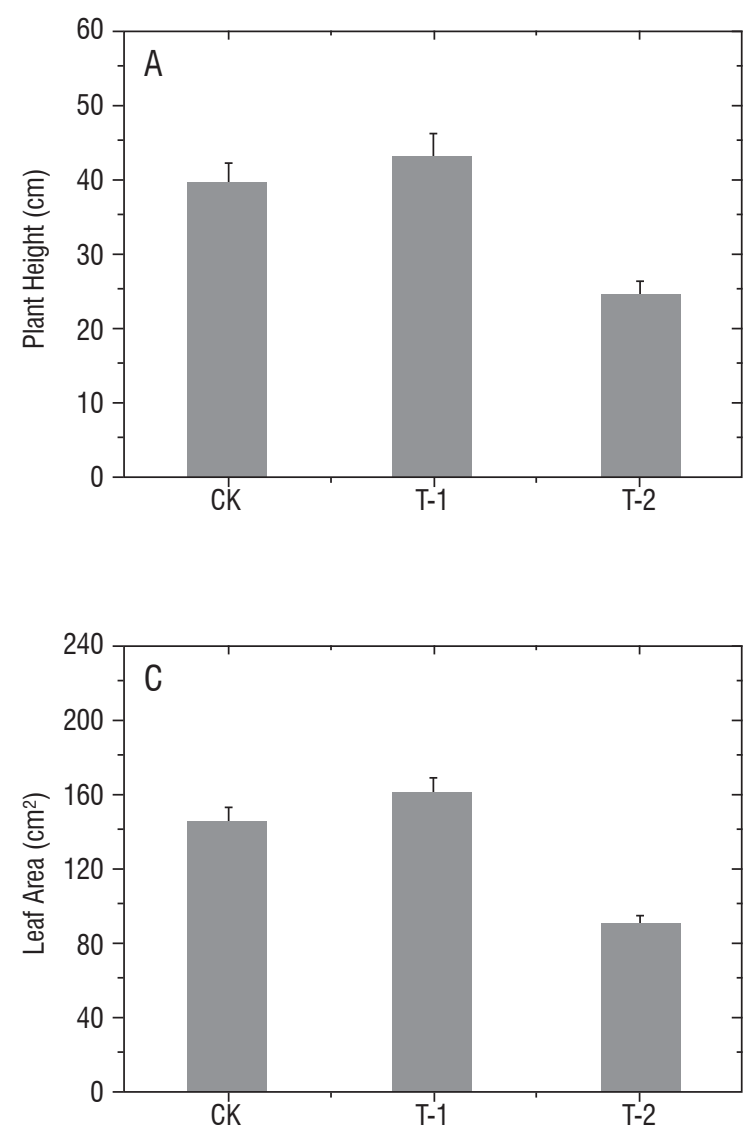

Statistical analysis: Date were analyzed with OriginPro8 (Version8E, OriginLab Corporation, Massachusetts, USA) and presented as means of three replicates \pm standard errors.

\section{RESULTS}

Plant growth: Figure 1 shows the effects of nitrate stress on plant growth. At $12 \mathrm{~d}$ after nitrate stress imposition, plant growth at $56 \mathrm{mmol} \mathrm{L}^{-1}$ nitrate was stimulated in plant height, stem diameter, leaf area, and leaf number of, respectively, $9 \%, 4 \%, 9 \%$, and $4 \%$ with respect to CK. By the same time, plant growth at $140 \mathrm{mmol}^{-1}$ nitrate suffered a severe reduction in plant height, stem diameter, leaf area, and leaf number of, respectively, 38\%, 26\%,39\%, and $38 \%$ with respect to $\mathrm{CK}$.
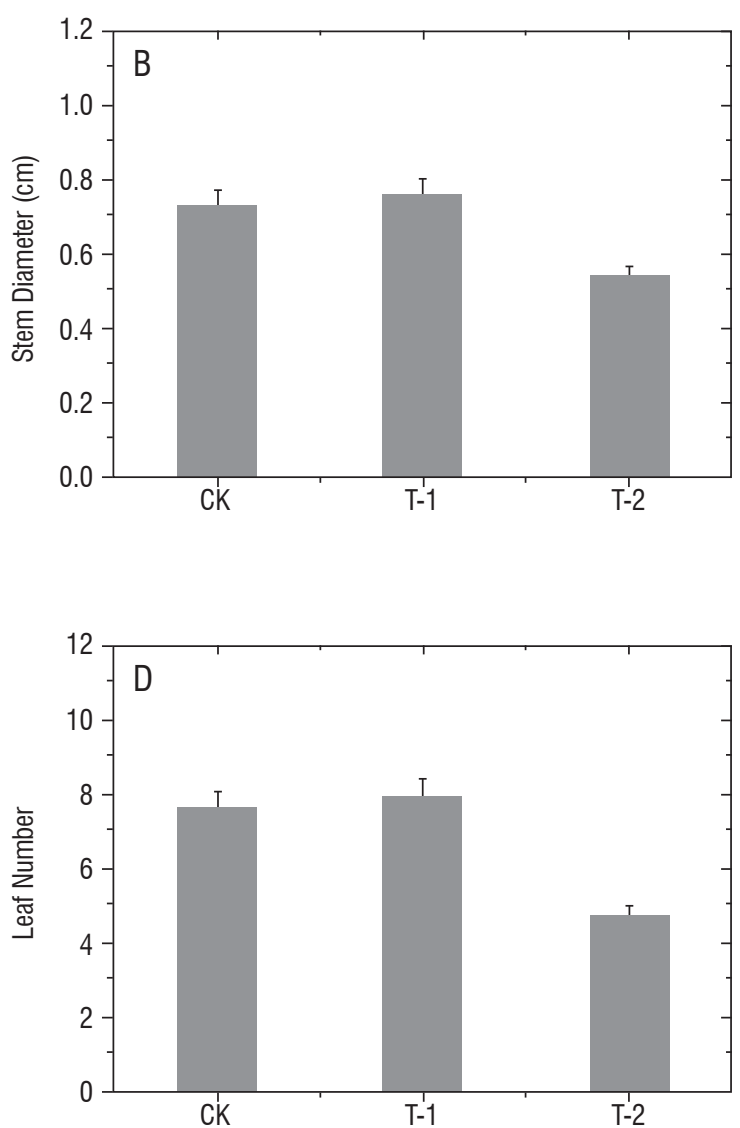

Figure 1. Changes in plant height $(A)$, stem diameter (B), leaf area (C) and leaf number (D) of cucumber seedlings at $12 \mathrm{~d}$ after treatment. Plants were grown in nutrient solutions containing 14 (CK), $56(\mathrm{~T}-1)$, and $140 \mathrm{mmol} \mathrm{L}^{-1}(\mathrm{~T}-2)$ nitrate, respectively. Vertical bars represent standard errors $(n=3)$. 
Photosynthetic rate: Figure 2 shows changes of photosynthetic rate in the leaves of cucumber seedlings under three nitrate levels. Photosynthetic rate of CK seedlings had few changes over treatment course. During the first $2 \mathrm{~d}$, photosynthetic rate of $\mathrm{T}-1$ seedlings increased by $27 \%$ with respect to $\mathrm{CK}$. Thereafter, the rate recovered gradually to the level of CK. Compared with CK, photosynthetic rate of T-2 decreased significantly over treatment course. At $12 \mathrm{~d}$, this decrease reached $40 \%$ with respect to $\mathrm{CK}$.

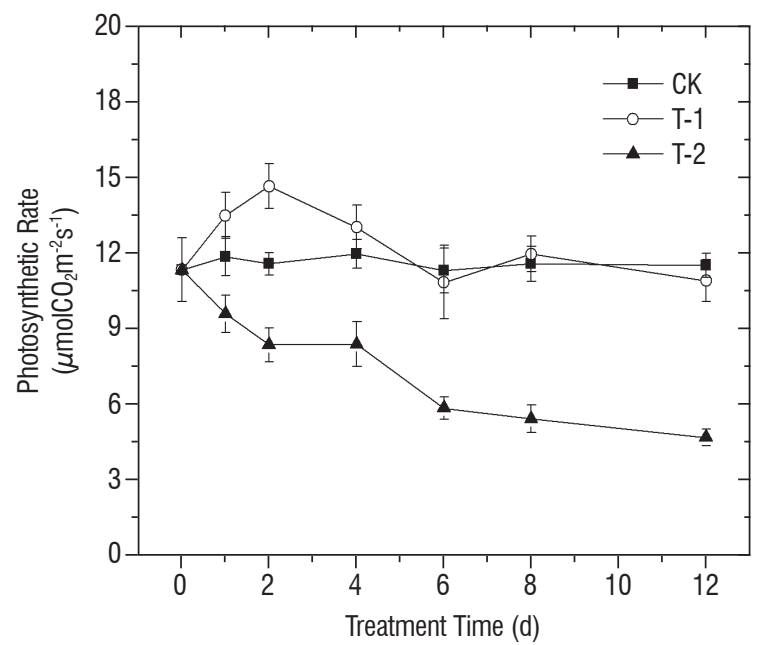

Figure 2. Effects of nitrate stress on photosynthetic rate in the leaves of cucumber seedlings. Plants were grown in nutrient solutions containing 14 (CK), 56 (T-1), and $140 \mathrm{mmol} \mathrm{L}^{-1}$ (T-2) nitrate, respectively, during $12 \mathrm{~d}$. Vertical bars represent standard errors $(n=3)$.

Photosynthetic pigment content: Figure 3 shows changes of total photosynthetic pigment content, chlorophyll $\mathrm{a} / \mathrm{b}$ and carotenoids/chlorophyll in the leaves of cucumber seedlings under three nitrate levels. Over treatment course, photosynthetic pigment content, chlorophyll a/b and carotenoids/chlorophyll of CK seedlings had few changes. Photosynthetic pigment content of T-1 increased by $23 \%$ with respect to CK during the first $2 \mathrm{~d}$. Thereafter, the content gradually recovered to the level of CK. Chlorophyll a/b and carotenoids/chlorophyll had no significant difference from CK during treatment period. Compared with CK, photosynthetic pigment content of T-2 increased by $25 \%$ during the first $2 \mathrm{~d}$. Thereafter, the content gradually recovered to the level of CK. During the first $4 \mathrm{~d}$, there was no significant difference in chlorophyll $\mathrm{a} / \mathrm{b}$ and carotenoids/chlorophyll between $\mathrm{T}-2$ and CK. After $4 \mathrm{~d}$, chlorophyll a/b of T-2 increased gradually, whereas carotenoids/ chlorophyll decreased. At $12 \mathrm{~d}$, the chlorophyll a/b was $23 \%$ higher than CK, and the carotenoids/chlorophyll was $15 \%$ lower than CK.
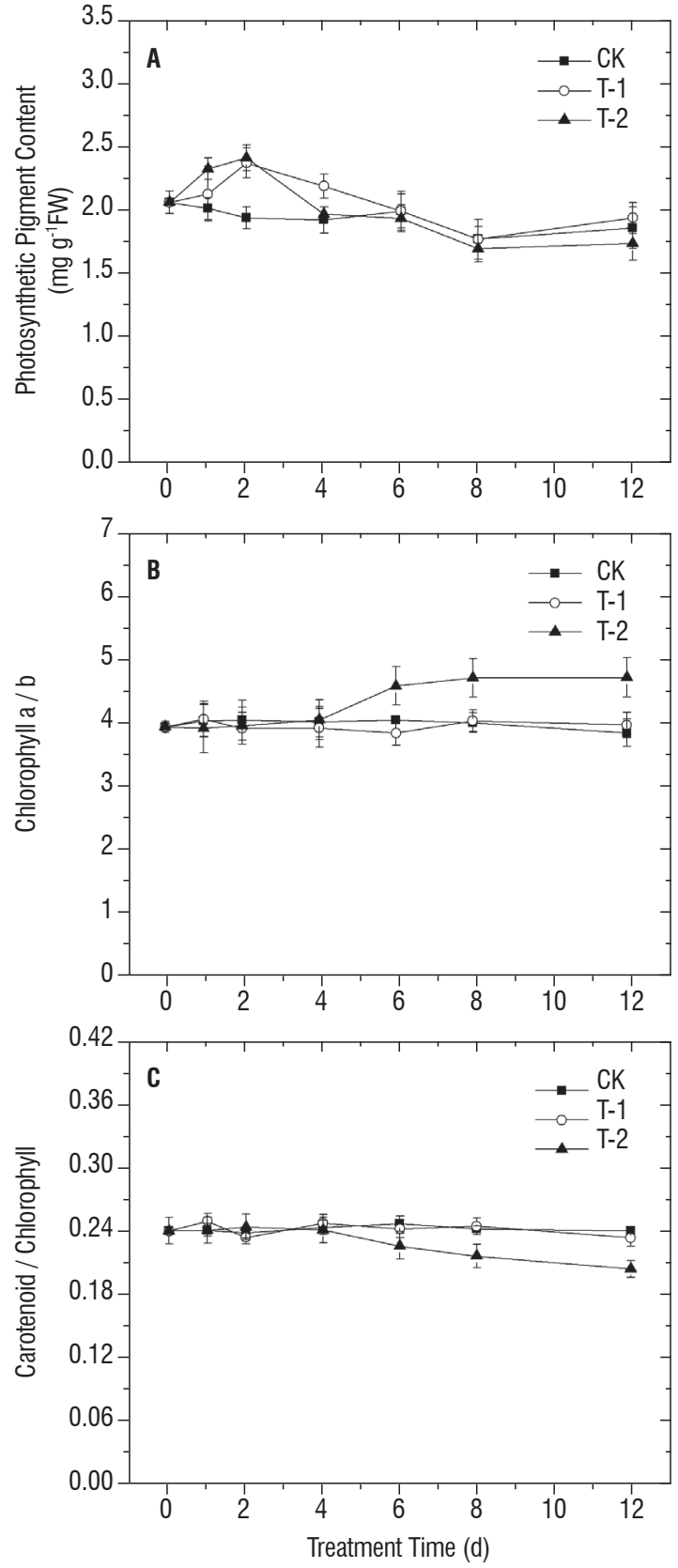

Figure 3. Effects of nitrate stress on photosynthetic pigment content (A), chlorophyll a/b (B), and carotenoids/chlorophyll (C) in the leaves of cucumber seedlings. Plants were grown in nutrient solutions containing 14 (CK), 56 (T-1), and $140 \mathrm{mmol}^{-1}(\mathrm{~T}-2)$ nitrate, respectively, during $12 \mathrm{~d}$. Vertical bars represent standard errors $(n=3)$.

Chlorophyll a fluorescence: Figure 4 shows changes of $\Phi_{P S I}, q P$, and $\mathrm{qN}$ in the leaves of cucumber seedlings under three nitrate levels. $\Phi_{\mathrm{PSII}}, \mathrm{QP}$, and $\mathrm{qN}$ of $\mathrm{CK}$ had few changes over treatment course. $\Phi_{\mathrm{PSII}}$ and $\mathrm{qP}$ of T-1 had no significant difference from CK over treatment course, and qN was a little higher than $\mathrm{CK}$ after $2 \mathrm{~d}$. During the first $2 \mathrm{~d}$, there was no significant difference in $\Phi_{P S \|}$ and $\mathrm{qP}$ between $\mathrm{T}-2$ and CK. After $2 \mathrm{~d}$, both $\Phi_{\mathrm{PS} \|}$ and $\mathrm{qP}$ 
of T-2 decreased to a great extend. At $12 \mathrm{~d}, \Phi_{\mathrm{PSI}}$ and $\mathrm{qP}$ lowered by $44 \%$ and $48 \%$ with respect to $\mathrm{CK}$, respectively. Over treatment course, a significant increase in qN of T-2 occurred. At $12 \mathrm{~d}$, qN increased by $72 \%$ with respect to $\mathrm{CK}$.
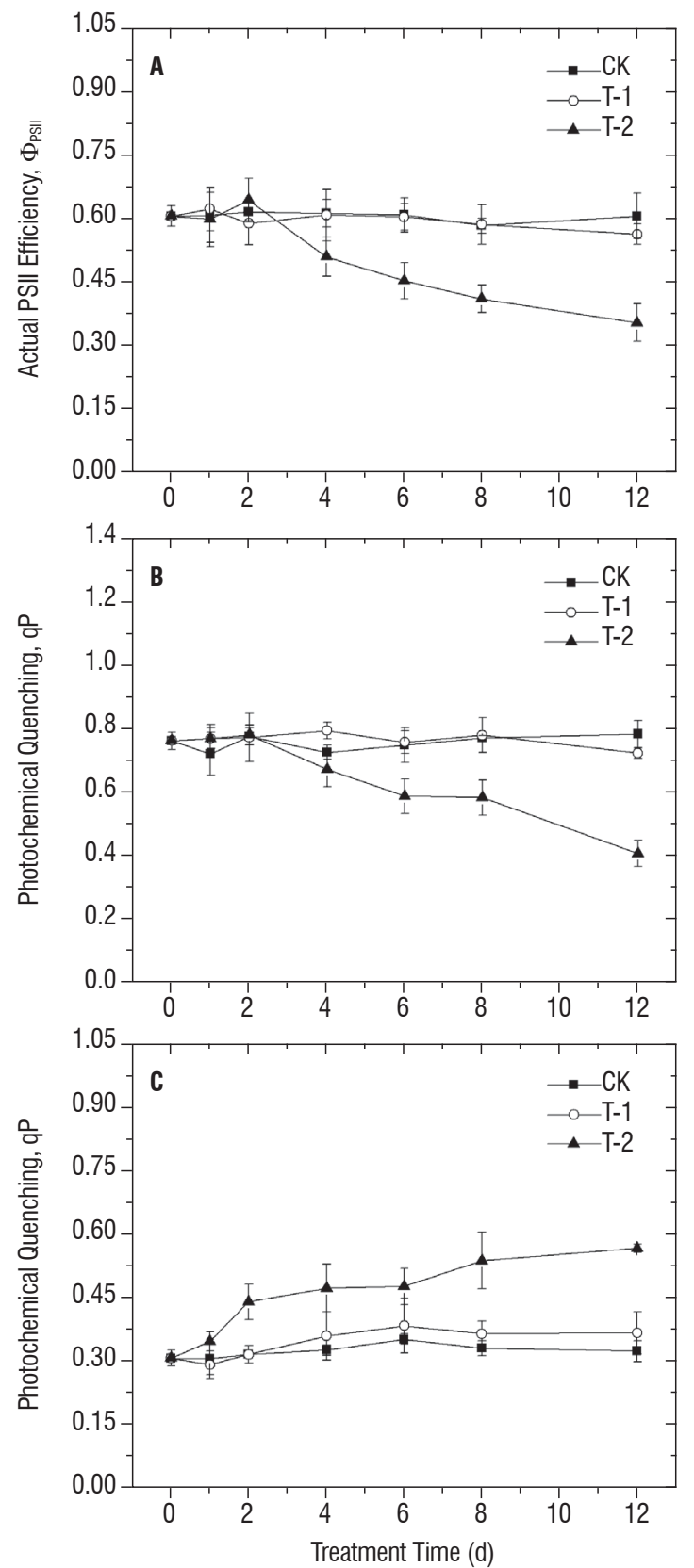

Figure 4. Effects of nitrate stress on $\Phi_{\mathrm{PSII}}(\mathrm{A}), \mathrm{qP}(\mathrm{B})$, and $\mathrm{qN}(\mathrm{C})$ in the leaves of cucumber seedlings. Plants were grown in nutrient solutions containing 14 (CK), 56 (T-1), and $140 \mathrm{mmol} \mathrm{L}^{-1}$ (T-2) nitrate, respectively, during $12 \mathrm{~d}$. Vertical bars represent standard errors $(n=3)$.

Hill reaction activity: Figure 5 shows changes of Hill reaction activity in the leaves of cucumber seedlings under three nitrate levels. A little fluctuation in Hill reaction activity of CK occurred over treatment course. With respect to CK, Hill reaction activity of T-1 slightly decreased. T-2 treatment resulted in a rapid decrease of Hill reaction activity of cucumber seedlings during treatment period compared with CK. At $12 \mathrm{~d}$, the activity of T-2 was $70 \%$ lower than CK.

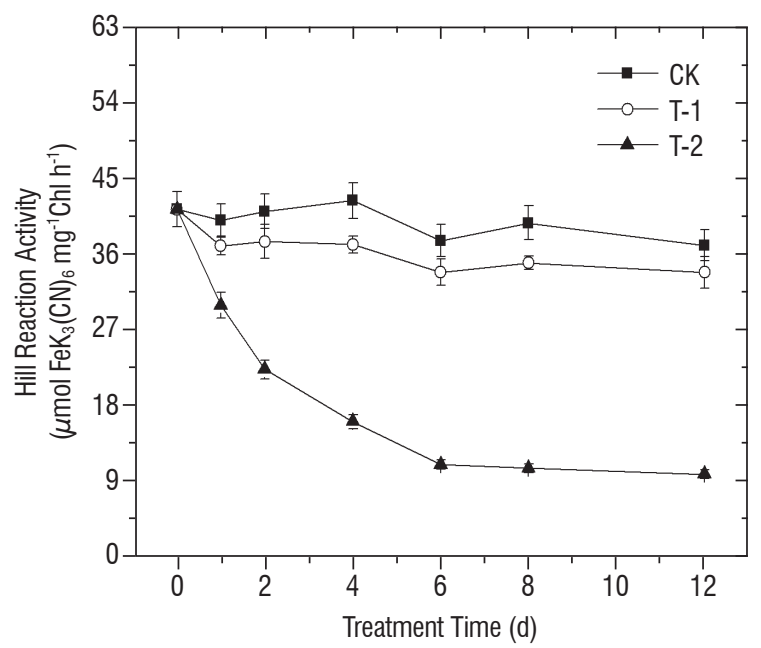

Figure 5. Effects of nitrate stress on Hill reaction activity in the leaves of cucumber seedlings. Plants were grown in nutrient solutions containing 14 (CK), 56 (T-1), and $140 \mathrm{mmol} \mathrm{L}^{-1}$ (T-2) nitrate, respectively, during $12 \mathrm{~d}$. Vertical bars represent standard errors $(n=3)$.

\section{DISCUSSION}

In the present study, a growth stimulation in cucumber seedlings was observed under $56 \mathrm{mmol} \mathrm{L}^{-1}$ nitrate (Figure 1 ), indicating that the additional input of nitrogen could promote plant growth (Burslem et al., 1996; Lawrence, 2003; Tanner et al., 1992). However, when nitrate concentration in nutrient solution increased to $140 \mathrm{mmol} \mathrm{L}^{-1}$, a significant growth reduction in cucumber seedlings was observed (Figure 1). The inhibition of cucumber growth by high nitrate stress could be explained by osmotic effects, in which high nitrate concentration in the root medium results in low water potential and eventually may lead to water stress (Table 2), or by specific ion effects, in which toxicity or deficiency of one or more ions may cause growth reduction under stress. The maintenance of optimal $\mathrm{C} / \mathrm{N}$ ratio is essential for plant growth and development. A high nitrate concentration in the root medium can result in entry of excessive $\mathrm{NO}_{3}$, and cause disturbance of $\mathrm{C} / \mathrm{N}$ radio. lonic imbalance which results from high concentration of nitrate may cause slow plant growth. It 
has been reported that root growth of many crops is severely inhibited by high saline concentration in the growing medium (Cramer et al., 1987). The reduction in root growth under salt stress reduces the volume of soil that can be explored by roots and therefore the quantity of nutritional ions, which moves by diffusion, is reduced from reaching plants. In addition, ions that transit the soil by mass flow (e.g. $\mathrm{NO}_{3}^{-}$) may accumulate near the root surface and compete with nutritional ions for membrane uptake sites. Excessive nitrate environment may therefore induce suboptimal nutrient concentrations in plant tissues (Kakafi and Bernstein, 1996). For example, high concentration of $\mathrm{NO}_{3}^{-}$has been shown to reduce $\mathrm{Cl}^{-}$(Bar et al., 1987) and phosphate (Lamaze et al., 1987) uptake, and high concentration of $\mathrm{K}^{+}$and $\mathrm{Ca}^{2+}$ may reduce the uptake of $\mathrm{Mg}^{2+}$ (Barber, 1995).

Short-term stimulation in photosynthetic rate was detected under mid-level nitrate during the first $2 d$ (Figure 2), a trend which could be considered a short-term response to nitrate stress because of the increase of photosynthetic pigment content (Figure 3A), increases in the following samplings were hardly significant due to the recovery of photosynthetic pigment content (Figure 3A). High-level nitrate resulted in substantial decrease of photosynthetic rate over treatment course (Figure 2). High nitrate concentration can impose both ionic and osmotic stresses on cucumbers. Stomatal closure, which increases the diffusive resistance to the entry of $\mathrm{CO}_{2}$ into the leaf (Sharp and Boyer, 1986), is often a rapid initial response to salt stress and can result in reduction of photosynthetic rate. In wheat, James et al. (2002) has shown that a stressinduced reduction in stomatal conductance was seen when the leaf emerged, but after some time there was a further decline, probably caused by chloroplast inhibition deriving from salt toxicity, which decreased the demand for $\mathrm{CO}_{2}$. Yang (2008) reported that long-term nitrate stress resulted in large accumulation of $\mathrm{NH}_{3}$ in cucumber seedlings, which was very toxic to plants (Cao et al., 2009) and could seriously damage photosynthetic electron flow (Izawa, 1977).

Photosynthetic pigment content plays a critical role in photosynthesis. Pigments can absorb solar energy and transfer it to chemical energy used for synthesis of ATP and glucose. A positive correlation between leaf nitrogen content and the photosynthetic pigment content is well documented for a number of plant species (Bojovic and Stojanovic, 2005; Fritshi and Ray, 2007; Houles et al., 2007; Sabo et al., 2002). In the present study, not only mid- but also high-level nitrate resulted in the increase of photosynthetic pigment content during early treatment period (Figure 3A). But at the same time a significant decrease in photosynthetic rate occurred under high-level nitrate (Figure 2), revealing that the chlorophyll content was not certainly related to the photosynthesis rate, especially under stress conditions. Pulkrabek (1998) and Siddiqu et al.(2006) have reported similar changes in sugar beet. With the increase of treatment time, photosynthetic pigment content of $\mathrm{T}-1$ and T-2 gradually recovered to the level of CK (Figure 3A). However, the underlying mechanisms are possibly different. In $\mathrm{T}-1$ seedlings, dilution effect caused by the stimulation of plant growth (Figure 1) may play an important role in the recovery of photosynthetic pigment content. Inhibition of synthesis and stimulation of decomposition possibly cause the recovery under high nitrate stress (Reddy and Vora, 1986; Santos and Caldeira, 1999). Environmental stress severely affects not only photosynthetic pigment content but chlorophyll $\mathrm{a} / \mathrm{b}$ and carotenoids/chlorophyll. In the present study, high nitrate stress resulted in the increase of chlorophyll $\mathrm{a} / \mathrm{b}$ and the decrease of carotenoids/chlorophyll (Figure 3B, 3C). This is in accordance with the results reported by Ma et al.(1997). The increase of chlorophyll $\mathrm{a} / \mathrm{b}$ is possibly due to less sensitivity of chlorophyll a to salt stress than chlorophyll b (Stoeva and Kaymakanova, 2008). The decrease of carotenoids/chlorophyll indicates that high nitrate stress may cause an increase in zeaxanthin and degradation of $\beta$-carotene, which are apparently involved in protection against photoinhibition (Sharma and Hall, 1991).

Photosystem II is considered to play an important role in the response of higher plants to environmental stress (Baker, 1991). The reduction of $\mathrm{CO}_{2}$ assimilation by nitrate stress should therefore be reflected in the PSII behavior. Chlorophyll a fluorescence is a rapid and non-intrusive tool used to screen varieties for PSII under salt stress (Maxwell and Johnson, 2000). It has be reported that $\Phi_{\mathrm{PSII}}$ and $\mathrm{qP}$ significantly decreased, but $\mathrm{qN}$ increased substantially under saline conditions (Corney et al., 2003; Netondo et al., 2004). In the present study, high nitrate stress resulted in significant decrease of $\Phi_{\mathrm{PS} \|}$ and $\mathrm{qP}$, and increase of qN (Figure 4A, $4 B, 4 C)$. The decrease of $\Phi_{P S \|}$ and $q P$ reflects that less of the absorbed photon-energy captured by the light harvesting system is used in photochemical reaction. As a result, the amount of excessively absorbed photon flux is greater in nitrate-stressed leaves than in normal leaves, particularly under high photon flux. The excessively absorbed photo flux 
can potentially lead to the production of ${ }^{1} \mathrm{O}_{2}$ and reduced reactive oxygen species, causing damage to photosynthetic apparatus (Han et al., 2009). The increase in qN may reflect a reduced demand for products of electron transport and, hence, increased heat dissipation. These results suggest that high-level nitrate stress may reduce photosynthesis through its direct effect on the photosynthetic apparatus.

With the increase of nitrate concentration, the rate of Hill reaction in cucumber seedlings was inhibited (Figure 5). This is similar to the results under salt stress reported by Tajdoost et al. (2007). The inhibition of Hill reaction possibly results from nitrate stress damage on photosynthetic systems and oxygen evolving complex (Allakhverdiev et al., 2000). Nitrate stress imposes a water stress because of low osmotic potential (Table 2) and may affect a wide variety of metabolic activities (Parida and Das, 2005). Krieger-Liszkay (2004) has proposed that the active oxygen forms could destroy the proteins, lipids, and important cell components, which could secondarily lead to damage in photosynthetic systems. In addition, $\mathrm{NH}_{3}$ toxicity deriving from excessive accumulation of $\mathrm{NH}_{3}$ under high nitrate stress may also lead to severe inhibition of Hill reaction activity (Izawa, 1977; Yang, 2008). The inhibition of Hill reaction activity in turn decreases the reduction of NADP+ and phosphorylation of ADP, which will result in a strong inhibition of $\mathrm{CO}_{2}$ assimilation.

In conclusion, high-level nitrate stress may reduce photosynthesis through its effects not only on stomatal conductance but on the photosynthetic apparatus.

Acknowledgements: We thank Xintai Research Institute of Cucumber, China, for kindly providing plant materials. This work has been supported by National Natural Science Foundation of China (grant No.: 30471187).

\section{REFERENCES}

Allakhverdiev SI, Sakamato A, Nishiyama Y, Inaba M (2000) Ionic and osmotic effects of NaCl-induced inactivation of photosystems I and II in Synechococcus sp. Plant Physiol. 123: 1047-1056.

Allison FE (1966) The fate of nitrogen applied to soils. Advan. Agron. 18: 219-258.

Baker NR (1991) A possible role for photosystem II in environmental perturbations of photosynthesis. Physiol. Plant. 81: 563-570.

Bar Y, Kafkafi U, Lahav E (1987) Nitrate nutrition as a tool to reduce chloride toxicity in avocado. S. Afr. Avocado Grower Assoc. Yrb. 10: 47-48.

Barker SA (1995) Soil Nutrient Bioavailability: A Mechanic Approach. Wiley Interscience, New York, USA.
Barker AV, Mills HA (1980) Ammonium and nitrate nutrition of horticultural crops. Hort. Rev. 2: 395-423.

Bojovic B, Stojanovic J (2005) Chlorophyll and carotenoid content in wheat cultivars as a function of mineral nutrition. Arch. Bio. Sci. 57: 283-290.

Bongi G, Loreto F (1989) Gas-exchange properties of salt-stressed olive (Olea europea L.) leaves. Plant Physiol. 90: 1408-1416.

Burslem DFRP, Grubb PJ, Turner IM (1996) Responses to simulated drought and elevated nutrient supply among shade-tolerant tree seedling of lowland forest in Singapore. Ecology 74: 104-112.

Cao T, Xie P, Ni LY, Zhang M, Xu J (2009) Carbon and nitrogen metabolism of an eutrophication tolerative macrophyte, Potamogeton crispus, under $\mathrm{NH}_{4}{ }^{+}$ stress and low light availability. Environ. Exp. Bot. 66: 74-78.

Corney HJ, Sasse NF, Ades PK (2003) Assessment of salt tolerance in eucalypts using chlorophyll fluorescence attributes. New Forests 26: 233246.

Cramer GR, Lynch J, Läuchli A, Epstein E (1987) Influx of $\mathrm{Na}^{+}, \mathrm{K}^{+}$, and $\mathrm{Ca}^{2+}$ into roots of salt-stressed cotton seedlings. Plant Physiol. 83: 510-516.

Debouba M, Maâroufi-Dghimi H, Suzuki A, Ghorbel MH, Gouia H (2007) Changes in growth and activity of enzymes involved in nitrate reduction and ammonium assimilation in tomato seedlings in response to $\mathrm{NaCl}$ stress. Ann. Bot. 99: 1143-1151.

Delfine S, Alvino A, Villani MC, Loreto F (1999) Restrictions to carbon dioxide conductance and photosynthesis in spinach leaves recovering from salt stress. Plant Physiol. 119: 1101-1106.

Foyer $\mathrm{CH}$, Noctor C (2002) Photosynthetic Nitrogen Assimilation and Associated Carbon and Respiratory Metabolism. Springer-Verlag, Berlin, Germany.

Fritchi FB, Ray JD (2007) Soybean leaf nitrogen, chlorophyll content, and chlorophyll a/b ratio. Photosynthetica 45: 92-98.

Gao QH, Wang XF, Shi QH, Yang FJ, Wei M (2008) Effects of lanthanum on the plant growth and leaf anti-oxidative enzyme activities of cucumber seedlings under nitrate stress. Chin. J. Appl. Ecol. 19: 976-980.

Genty B, Briantais JM, Baker NR (1989) The relationship between the quantum yield of photosynthetic electron transport and quenching of chlorophyll fluorescence. Biochim. Biophys. Acta 990: 87-92.

Gorham PR (1955) p. 22. In: S.P. Colowick, and N.O. Kaplan (Eds), Methods Enzymol 1. Academic Press Inc., New York, USA.

Guo SR (2004) Soilless Culture. China Agricultural Press, Beijing, China. pp. 114.

Han S, Tang N, Jiang HX, Yang LT, Lie Y, Chen LS (2009) $\mathrm{CO}_{2}$ assimilation, photosystem II photochemistry, carbohydrate metabolism and antioxidant system of citrus leaves in response to boron stress. Plant Sci. 176: 143153

Houles V, Guerfi M, Mary B (2007) Elaboration of a nitrogen nutrition indicator for winter wheat based on leaf area index and chlorophyll content for making nitrogen recommendations. Euro. J. Agron. 27: 1-11.

Ikan R (1969) Natural Products, A Laboratory Guide. Academic Press, New York, USA

Izawa S (1977) Inhibition of electron transport, p. 266-279. In: A. Trebst, and M. Avron (Eds.), Photosynthesis I: Photosynthetic electron transport and photophosphorylation. Speinger-Verlag, Berlin, Germany.

James RA, Rivelli AR, Munns R, von Caemmerer S (2002) Factors affecting $\mathrm{CO}_{2}$ assimilation, leaf injury and growth in salt-stressed durum wheat. Funct. Plant Bio. 29: 1393-1403.

Jiang WJ, Qu DY (2000) Present situation and suggestion for sustainable development of protected horticulture in mainland China. Chin. Agri. Sci. Bul. 16: 61-63.

Ju XT, Kou CL, Christie P, Dou ZX, Zhang FS (2007) Changes in the soil environment from excessive application of fertilizers and manures to two 
contrasting intensive cropping systems on the North China Plain. Environ. Pollut. 145: 497-506.

Kakafi U, Berstein N (1996) p. 435-453. In: Y. Waisel, A. Eshel, and U. Kakafi (Eds.), Plant Roots: The Hidden Half, Marcel Dekker Inc., New York, USA.

Kitamura Y, Yano T, Honna T, Yamamoto S, Inosako K (2006) Causes of farmland salinization and remedial measures in the Aral Sea basin-research on water management to prevent secondary salinization in rice-based cropping system in arid land. Agric. Water Manage. 85: 1-14.

Krieger-Liszkay A (2004) Singlet oxygen productiom in photosynthesis. J. Exp. Bot. 56: 337-346.

Lamaze T, Sentenac H, Grignon C (1987) Orthophosphate relations of root: $\mathrm{NO}_{3}{ }^{-}$effects on orthophosphate influx, accumulation and secretion into the xylem. J. Ex. Bot. 38: 923-934.

Lauteri M, Scartazza A, Guido MC, Brugnoli E (1997) Genetic variation in photosynthetic capacity, carbon isotope discrimination and mesophyll conductance in provenances of Castanea sativa adapted to different environments. Funct. Ecol. 11: 675-683.

Lawrence D (2003) The response of tropical tree seedlings to nutrient supply: meta-analysis for understanding a changing tropical landscape. J. Tro. Eco. 19: 239-250.

Liu J, Zhu JK (1998) A calcium sensor homolog required for plant salt tolerance. Science 280: 1943-1945.

Loreto F, Di Marco G, Tricoli D, Sharkey TD (1994) Measurements of mesophyll conductance, photosynthetic electron transport and alternative electron sinks of field grown wheat leaves. Photosynth. Res. 41: 397-403.

Lü J, Wang XF, Wei M, Yang FJ, Gao QH, Du DL, Yang XY (2007) Effect of different salt treatments on growth and physiological characteristics of cucumber seedlings. Plant Nutr. Fert. Sci. 13: 1123-1128.

Ma HC, Fung L, Wang SS, Altman A, Huttermanna A (1997) Photosynthetic response of Populus euphratica to salt stress. For. Ecol. Manage. 93: 55-61.

Maxwell K, Johnson GN (2000) Chlorophyll fluorescence: a practical guide. J. Exp. Bot. 51: 659-668.

Netondo GW, Onyango JC, Beck E (2004) Sorghum and salinity: II. Gas exchange and chlorophyll fluorescence of sorghum under salt stress. Crop Sci. 44: 806-811.

Parida AK, Das AB (2005) Salt tolerance and salinity effects on plants. Ecotoxicol. Environ. Safety 60: 324-349.

Pulkrabek J (1998) Possibilities to determine changes in chlorophyll content in leaves of sugar beet (Beta vulgaris L.) by Minolta chlorophyllmeter. Sci. Agri. Bohemica 165: 121.

Reddy MP, Vora AB (1986) Changes in pigment composition, Hill reaction activity and saccharides metabolism in bajra (Pennisetum typhoide S.\&H.) leaves under $\mathrm{NaCl}$ salinity. Photosynthetica 20: 50-55.

Robbins NS, Pharr DM (1987) Leaf area prediction model for field growth cucumbers. Hortscience 22: 1264-1266.

Sabo M, Teklic T, Vidovic I (2002) Photosynthetic productivity of two winter wheat varieties (Triticum aestivum L.). Rostlinna Vybroba 48: 80-86.
Santos C, Caldeira G (1999) Comparative responses of helianthusannuus plants and calli exposed to $\mathrm{NaCl}$ growth rate and osmotic regulation in intact plants and calli. J. Plant Physiol. 155: 769-777.

Sharma PK, Hall DO (1991) Interaction of salt stress and photoinhibition on photosynthesis in barley and sorghum. J. Plant Physiol. 138: 614-619.

Sharp RE, Boyer JS (1986) Photosynthesis at low water potentials in sunflower: Lack of photoinhibitory effects. Plant Physiol. 82: 90-95.

Siddiqui MH, Khan MMA, Khan MN, Mohammad F, Naeem M (2006) Hill Reaction, photosynthesis and chlorophyll content in non-sugar-producing (Turnip, Brassica rapa L.) and sugar-producing (Sugar beet, Beta vulgaris L.) root crop plants. Turk. J. Biol. 30: 153-155.

Stepien P, Johnson GN (2009) Contrasting responses of photosynthesis to salt stress in the glycophyte Arabidopsis and the halophyte Thellungiella: role of the plastid terminal oxidase as an alternative electron sink. Plant Physiol. 149: 1154-1165.

Stoeva N, Kaymakanova M (2008) Effect of salt stress on the growth and photosynthesis rate of salt bean plants (Phaseolus vulgaris L.). J. Cent. Euro. Agri. 9: 385-392.

Strain HH, Svec WA (1966) Extraction, separation, estimation and isolation of the chlorophylls, p. 21-66. In: G.R. Vernon, and G.R. Seely (Eds.), The Chlorophyll. Academic Press, New York, USA.

Tajdoost S, Farboodnia T, Heidari R (2007) Salt pretreatment enhance salt tolerance in Zea mays L. seedings. Pakistan J. Biol. Sci. 10: 2086-2090.

Tanner EVJ, Kapos V, Franco W (1992) Nitrogen and phosphorus fertilization effects on Venezuelan montane forest trunk growth and littlefall. Ecology 73 : 78-86.

van Kooten 0, Snel JFH (1990) The use of chlorophyll fluorescence nomenclature in plant stress physiology. Photosyn. Res. 25: 147-150.

Vishniac W (1957) p. 342-343. In: S.P. Colowick, and N.0. Kaplan (Eds.), Methods Enzymol 4. Academic Press Inc., New York, USA.

Yang XY (2008) Study on Effects of Nitrate Stress on Nitrogen Assimilation of Cucumber (Cucumis sativus L.) Seedlings. Master Degree Dissertation of Shandong Agricultural University, Tai'an, Shandong, China.

Yu HY, Li TX, Zhou JM (2005) Secondary salinization of greenhouse soil and its effects on soil properties. Soils 37: 581-586.

Zhu JH, Li XL, Christie P, Li JL (2005) Environmental implications of low nitrogen use efficiency in excessively fertilized hot pepper (Capsicum frutescens L.) cropping systems. Agric. Ecosys. Environ. 111: 70-80.

Zhu JK (2002) Salt and drought stress signal transduction in plants. Ann. Rev. Plant Biol. 53: 247-273. 